\title{
The Capital Asset Pricing Model: An Overview of the Theory
}

\author{
Mona A. Elbannan ${ }^{1}$ \\ ${ }^{1}$ Faculty of Management Technology, German University in Cairo, Cairo, Egypt \\ Correspondence: Mona A. Elbannan, Faculty of Management Technology, German University in Cairo, New \\ Cairo City 11835, Cairo, Egypt. Tel: 20-2-2758-9990-8. E-mail: mona.elbannan@guc.edu.eg
}

Received: September 24, 2014

Accepted: October 29, 2014

Online Published: December 25, 2014

doi:10.5539/ijef.v7n1p216

URL: http://dx.doi.org/10.5539/ijef.v7n1p216

\begin{abstract}
Although the Capital Asset Pricing Model (CAPM) has been one of the most useful and frequently used theories in determining the required rate of return of a security, the application of this model has been controversial since early 1960s. The CAPM was introduced by Jack Treynor, William Sharpe, John Lintner and Jan Mossin independently, building on the earlier work of Harry Markowitz on diversification and modern portfolio theory. In theory, the capital asset pricing model is employed to set the investor required rate of return on a risky security given the non-diversifiable firm-specific risk, as the systematic risk will be eliminated in a well-diversified portfolio. This research aims to shed the light on this model by discussing the assumptions, the evolution of the Sharpe and Lintner model, and reviewing the literature on the relaxation of model assumptions and the critiques of the CAPM. Finally, the Arbitrage Pricing Model as an extension for the CAPM will be discussed.
\end{abstract}

Keywords: Capital Asset Pricing model (CAPM), Beta, Intertemporal Capital Asset Pricing model (ICAPM), Consumption Capital Asset Pricing model (CCAPM), Arbitrage Pricing theory (APT)

\section{Introduction}

The Capital Asset Pricing Model (CAPM) was introduced by William Sharpe (1964) and John Lintner (1965), resulting in a Nobel Prize for Sharpe in 1990. It is built on the earlier work of Harry Markowitz (1959) who developed the "mean-variance model" or model of portfolio choice. The model is used to determine a theoretically appropriate required rate of return of an asset, and thus the price could be also expected if firms can estimate the expected cash flows.

Markowitz (1959) model suggests that investors choose a portfolio that will minimize the variance of portfolio return, given a specific level of expected return, or maximize expected return, given a specific level of variance. Thus, the Markowitz model is called a "mean-variance model" and assumes investors are efficient, risk averse and utility maximizing investors who select points that are located on the efficient frontier (called the minimum variance frontier) and hence, the portfolio selected depends on investor's risk-return utility function. Therefore, investors choose portfolios for only a single period of investment and focus on the mean and variance of their investment return, i.e. choose a portfolio at time $\mathrm{t}-1$, which produces a stochastic (randomly determined) return at $\mathrm{t}$.

Sharpe (1964) and Lintner (1965) develop Markowitz model which depends on the tradeoff between risk and return, and introduce their models with additional two key assumptions. The first assumption is borrowing and lending at a risk free rate, that is, investors can borrow or lend any amount of money at the risk-free rate of return which is the same for all investors and does not depend on the amount borrowed or lent. The second assumption is that all investors have homogenous expectations which results in estimating identical probability distributions for future return, that is, total agreement on the distribution of asset returns from t- 1 to $t$.

Although the CAPM is widely used as it measures the expected rate of return of a security and relates it to expected risk, however, the empirical evidence shows that it is "poor enough to invalidate the way it is used in applications" (Fama \& French, 2004).

The study begins by discussing the development of the CAPM, the assumptions that it is build on, and the theoretical failings that resulted from simplifying many of these assumptions. Then the paper will review the articles that deal with the shortcomings of the CAPM which raises the need for alternative models such as the Arbitrage Pricing Model (APT). 


\section{The Logic of the CAPM and Assumptions of the Model}

The CAPM is relying on several assumptions developed by Markowitz (1959), and then Sharpe (1964) and Lintner (1965) extend Markowitz model and add two critical assumptions to the Markowitz model. These assumptions will be discussed in more details.

\subsection{Assumptions of the Model}

The CAPM extends the market portfolio model introduced initially by Markowitz (1959) who argue that investors are risk averse investors and will choose a portfolio by trading off between risk and return for one investment period. Therefore, investors will choose the efficient portfolios that minimize the variance of portfolio return, given specific level of expected return, or maximize expected return, given specific level of variance. Thus, the Markowitz model is also called a "mean-variance model."

Sharpe (1964) and Lintner (1965) add two main assumptions to Markowitz model, homogeneity of investor expectations, i.e. investors choose the same distribution of asset returns from $t-1$ to $t$, and all investors can borrow or lend at risk-free rate. Therefore, Capital Market theory assumptions will be the same assumptions of Markowitz portfolio model, in addition to the two assumptions added by Sharpe (1964) and Lintner (1965), these assumptions are: 1) All investors take a position on the efficient frontier, where all investments are maximizing utility. Investors are risk averse, utility maximizing and focus only on their return (mean) and the related risk (variance). The exact location on the efficient frontier which investors take and the portfolio they select will depend on their utility function and the trade-off between risk and return. 2) Investors can borrow or lend any funds at the risk-free rate of return (RFR). 3) All investors have homogenous expectations which mean that they estimate the same distributions for the future rates of return. 4) All investors hold investments for the same one-period of time. 5) Investors are able to buy or sell portions from their shares of any security or a portfolio they hold. 6) There are no taxes or transaction costs on purchasing or selling assets. 7) There is no inflation or any change in interest rates. 8) Capital markets are in equilibrium, and all investments are fairly priced. Investors can not affect prices (Reilly \& Brown, 2003).

\subsection{Development of Sharpe-Lintner Model}

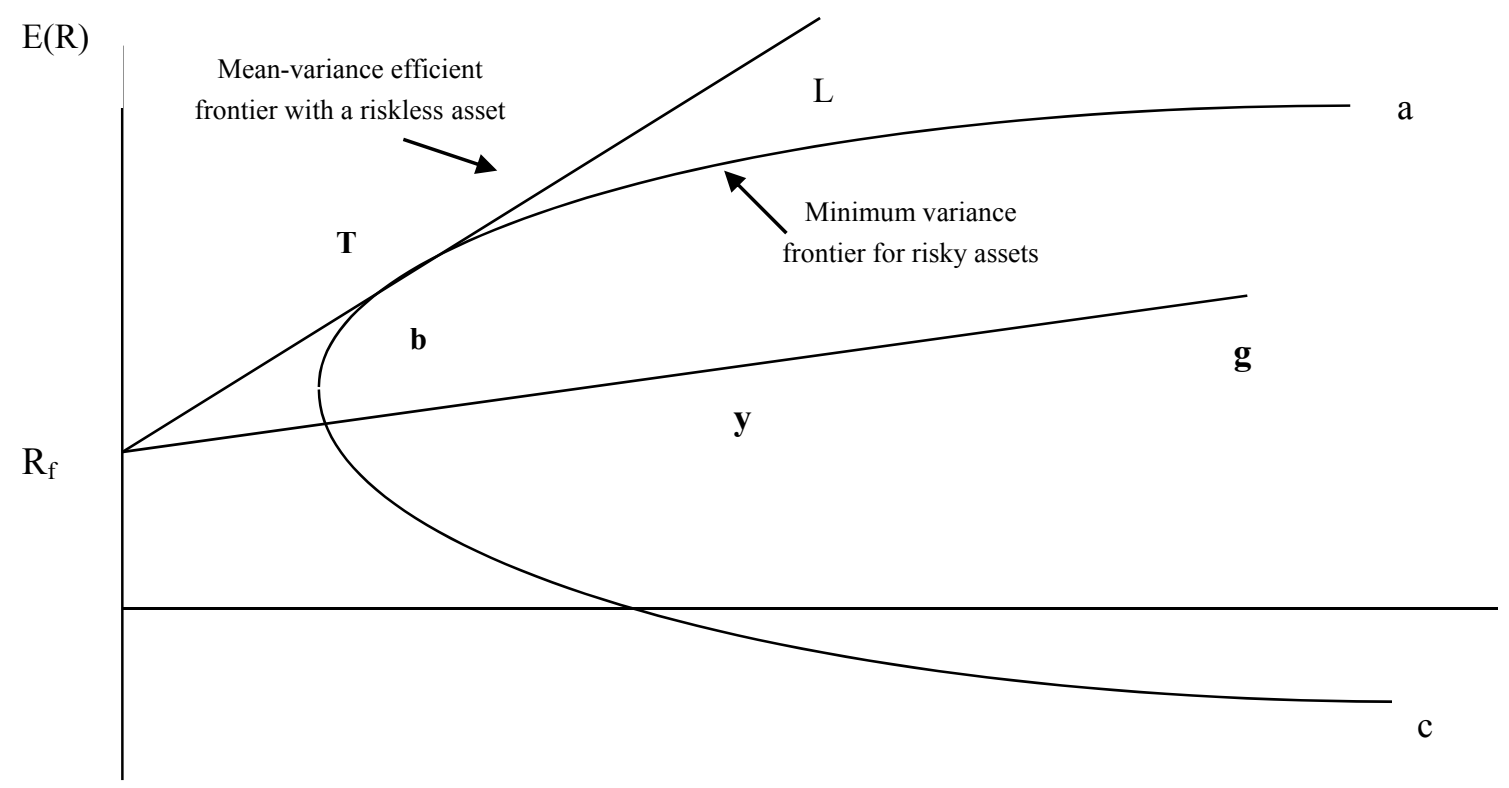

Figure 1. Investment opportunities

Source: Fama and French (2004).

Fama and French (2004) describe portfolio opportunities using the following figure. Figure (1) depicts the CAPM by combining the efficient frontier and the line extended from the risk free return point on the y-axis. The risk of the portfolio is measured by the standard deviation of portfolio return and shown on the horizontal axis; while the expected return of the portfolio is shown on the vertical axis. The minimum variance frontier, shown by the curve ( $a, b$, and $c)$, includes portfolios of risky assets with different combinations of expected return and 
risk that minimize risk at different levels of expected return or maximize return at different levels of risk. Portfolios on the efficient frontier do not include the risk-free rate of return for borrowing and lending. Investors will trade off between risk and expected return by taking different positions on the efficient frontier according to their risk preferences. For example, point (a) shows an investor who seeks high expected return and accordingly will be ready to accept high risk and volatility of return. At point (b), the investor can have moderate expected return with lower volatility. If there is no risk-free borrowing or lending, only portfolios above the point (b) along the curve ( $a, b$, and $c$ ) are efficient portfolios, since they maximize expected return at the same level of risk.

If the risk-free rate of return is added to the graph, shown by the point $R_{F}$, this means ability of borrowing and lending funds at the risk-free return. Thus set of efficient portfolios will move to be along the straight line $\mathrm{R}_{\mathrm{F}}-\mathrm{g}$. Investors can invest a proportion of their investment in a risk-free security and the remaining of their investment will be invested in a risky portfolio of assets. If investors choose to invest all their funds in the risk-free security then they will take a position at the point $\mathrm{R}_{\mathrm{F}}$ in Figure (1), a portfolio with zero risk and a risk-free rate of return. However if investors choose to invest a proportion only of their investment in the risk free return assets and the other portion in a risky portfolio, then they will take a position along the line $\mathrm{R}_{\mathrm{F}}-\mathrm{g}$ where combinations of risk-free lending and borrowing investments are possible along this line. Specifically, the set of points between $\mathrm{R}_{\mathrm{F}}$ and $\mathrm{y}$ show lending and investment with a risk-free rate, while the set of points lying between the points $\mathrm{y}$ and $\mathrm{g}$ on the straight line represent borrowing at the risk-free rate, with the proceeds from the borrowing used to increase investment in portfolio g. Figure (1) shows portfolios with risk-free lending or risk-free borrowing investments on the straight line between $\mathrm{R}_{\mathrm{F}}-\mathrm{g}$, where investors can borrow at the risk-free rate and use these borrowings to invest in portfolio g.

Tobin's (1958) "separation theorem," indicates that investors invest in efficient portfolios with risk-free borrowing and lending, that maximizes return for a given risk and minimizes risk for a given return, thus moving along the line from $R_{F}$ and to the left to the tangency portfolio $T$ in Figure (1). Thus, all efficient portfolios will include a mix of the risk-free asset and a risky portfolio, $\mathrm{T}$.

Fama and French (2004) clarify that when risk-free borrowing and lending are available, the expected return on assets will be equal to the risk-free rate, $\mathrm{R}_{\mathrm{F}}$ as assets returns are uncorrelated with the market return, $\mathrm{E}\left(\mathrm{R}_{\mathrm{ZM}}\right)$, must equal. The CAPM equation according to Sharpe and Lintner assumptions of risk-free borrowing and lending are expressed as follows:

$$
E\left(R_{i}\right)=R_{f}+\beta\left[E\left(R_{M}\right)-R_{f}\right]
$$

Where market Beta:

$$
\beta_{i M}=\frac{\operatorname{COV}\left(R_{i} \underline{R}_{M}\right)}{\sigma^{2}\left(R_{M}\right)}
$$

Where, $E\left(R_{i}\right)$ is the expected return on asset $i$, and $\beta$ is the market beta of asset $i$ that measures the sensitivity of the asset's return to variation in the market return. Beta is measured by the covariance of the asset return with the market return divided by the variance of the market return. $R_{f}$ is the risk free rate of return, and $R_{M}$ is the market return. From the sharpe-Lintner CAPM equation, the expected return on an asset is equal to the risk free rate of return $R_{F}$ plus a risk premium which consists of a market risk premium (the expected market return $E\left(R_{M}\right)$ minus the risk free interest rate $\mathrm{R}_{\mathrm{F}}$ ) times the market beta of the asset $i$. In other words, the expected return on any asset $\mathrm{i}$ is the risk-free interest rate, $\mathrm{R}_{\mathrm{F}}$, plus a risk premium, which is the asset's market beta, $\beta_{\mathrm{iM}}$, times the premium per unit of beta risk, $E\left(R_{M}\right)-R_{F}$. Markowitz developed analysis based on the expected utility maxim and proposed a general solution for the portfolio selection problem. Sharpe (1964) provides a model of individual investor behavior under conditions of risk by presenting the investor preferences in a family of indifference curves, which indicates higher level of utility as we move up, and then shows the equilibrium conditions for the capital market and derives the capital market line.

The model of investor behavior considers the investor as choosing from a set of investment opportunities the one which maximizes utility; thus choosing from among all possible plans the one on the indifference curve representing the highest level of utility.

The decision could be made on two stages: (1) find the set of efficient investment plans which whether have the same expected return and lower risk, or same risk and higher return, or higher return and lower risk. These plans that would be chosen will lie on a curve called investment opportunity curve. Then (2) choose one from among this set. Then Sharpe (1964) deals with the riskless assets or the asset with pure rate of interest and its risk is zero. All the combinations of any risky assets plus the riskless asset will lie along a straight line that is tangent to the investment opportunity curve. The author presents the ability to lend at the pure rate and invest in the risky 
portfolio on the investment opportunity curve, and the possibility of borrowing at the pure rate of interest. The choice will be first to choose the unique or optimum combination of risky assets, and second borrow or lend to obtain the particular point at which indifference curve is tangent to the line.

Sharpe determines two assumptions to derive conditions for equilibrium in the capital market, the first is assuming a common pure rate of interest with all investors able to borrow or lend funds on equal terms, second, assuming homogeneity of investor expectations. These assumptions are unrealistic assumptions, but the author emphasizes that the proper test of a theory is not the realism of its assumptions but the acceptability of its implications.

Figure (2) shows that an investor with indifference curve A will lend some of his funds at the pure interest rate to invest in the combination of assets at point $\theta$, while an investor with preferences curves $B$ will invest his funds in $\theta$, and an investor with indifference curves $\mathrm{C}$ would borrow at the pure interest rate to invest in combination $\theta$. That means that any point on the line PZ could be attained by borrowing or lending at the pure rate plus an investment in some combination of risky assets. The investment opportunity curve must be tangent to the capital market line PZ in equilibrium. Sharpe (1964) assures that diversification enables investor to escape all but the risk resulting from swings in the economic activity.

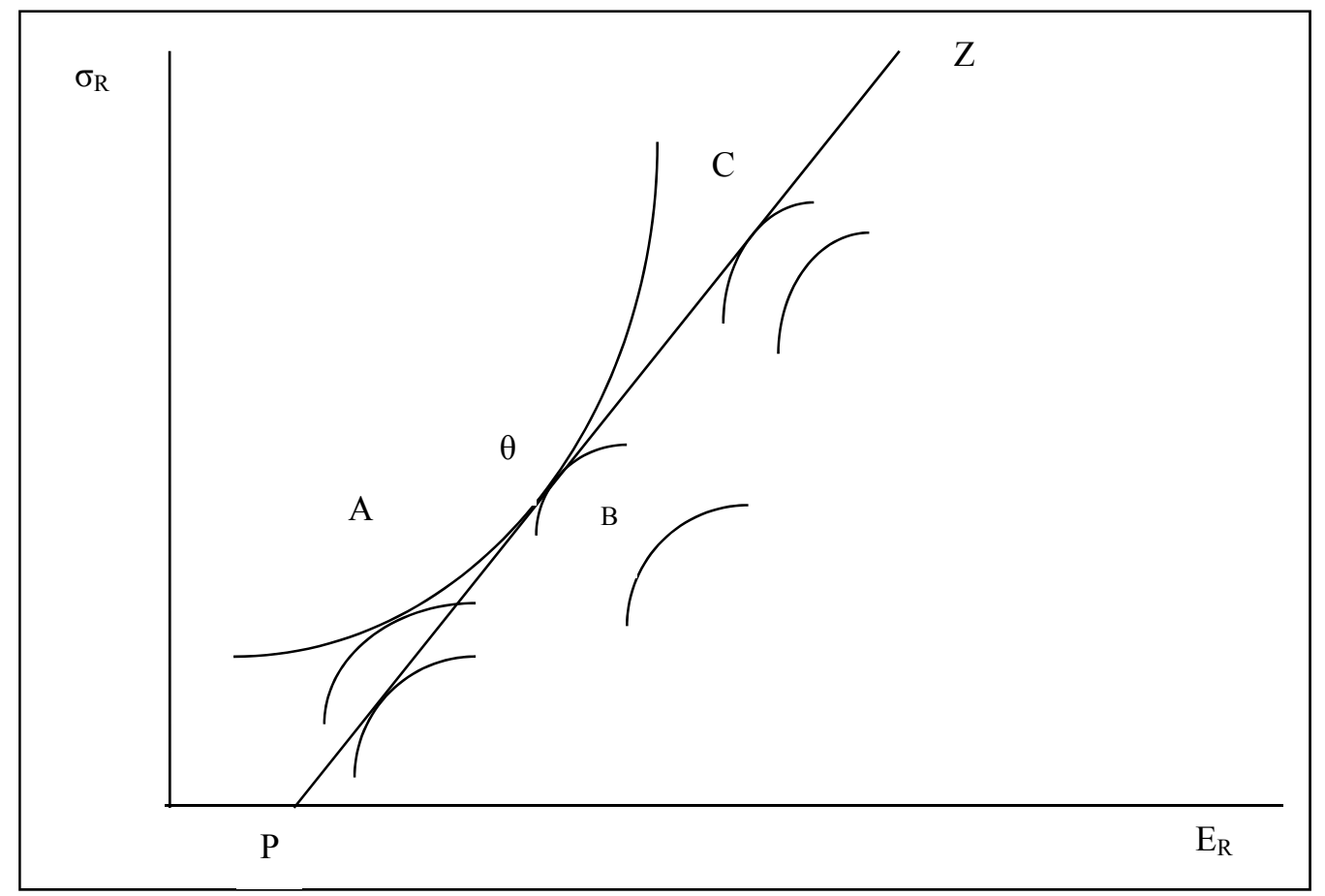

Figure 2. Indifference curves

Source: Sharp (1964).

Lintner (1965) argues that the problem of selecting optimal security portfolios by risk-averse investors who have the alternative of investing in risk free securities with a positive return (or borrowing at the same rate of interest) and who can sell short if they wish. Lintner (1965) develops various significant equilibrium properties within the risk asset portfolio, and establishes conditions under which stocks will be held long (short) in optimal portfolios even when risk premiums are negative (positive).

\section{The relaxation of assumptions for the Capital Asset Pricing Theory}

\subsection{Differential Borrowing and Lending Rates}

The inequality of borrowing and lending rates has been suggested by Friend and Blume (1970) as a possible cause of the apparent discrepancy between the observed ex-post relationship between the risk and return of New York stock Exchange securities and the ex-ante predications of the CAPM. These authors have argued that inequality between investor borrowing and lending rates would alone be expected to result in an ex-ante market risk-return trade off, where the risk of a security is measured by its beta coefficient, consisting of two straight 
lines resulting from borrowing and lending opportunities, connected by a curve which is iconcave with respect to the risk axis resulting from the set of efficient risky portfolios for which lending and borrowing opportunities would not improve an investor's position.

Reilly and Brown (2003) in attempt to discuss the relaxation of the assumption of borrowing and lending at risk free rates, assume unlimited ability of investors to invest at risk-free rate by buying government securities, but there are restrictions on borrowing unlimited funds at risk free rate because investors must pay a higher rate when borrowing money, accordingly there will be two different lines passing to the efficient frontier. Brennan (1971) allows for risk-free borrowing and lending, but at different interest rates, and derives some properties when investors are faced with divergent borrowing and lending rates and when these rates may vary among investors.

\subsection{Zero-Beta Model}

Black (1972) considers a model with risk-free lending but not borrowing, and this leads to a CAPM in which the Zero Beta rate of the market portfolio exceeds the riskless lending rate, but less than the borrowing rate. Black adds two assumptions to capital market equilibrium that are more restrictive than the usual assumptions used in the deriving the CAPM. First, there is no riskless asset and that no riskless borrowing or lending is allowed. Second, there is a riskless asset and that long positions in the riskless asset are allowed but that short positions in the riskless asset (borrowing) are not allowed. In both cases Black (1972) assumes that an investor can take unlimited long or short positions in the risky asset, and concludes that in both cases, the risky portion of every portfolio is a weighted combination of portfolios $\mathrm{m}$, and $\mathrm{z}$, where the portfolio $\mathrm{m}$ is the market portfolio, and portfolio $\mathrm{z}$ is the minimum variance zero beta portfolio. The line relating the expected return on an efficient portfolio to its $\beta$ is composed of two straight segments, where the segment for the lower risk portfolios has a greater slope than segment for the higher risk portfolios.

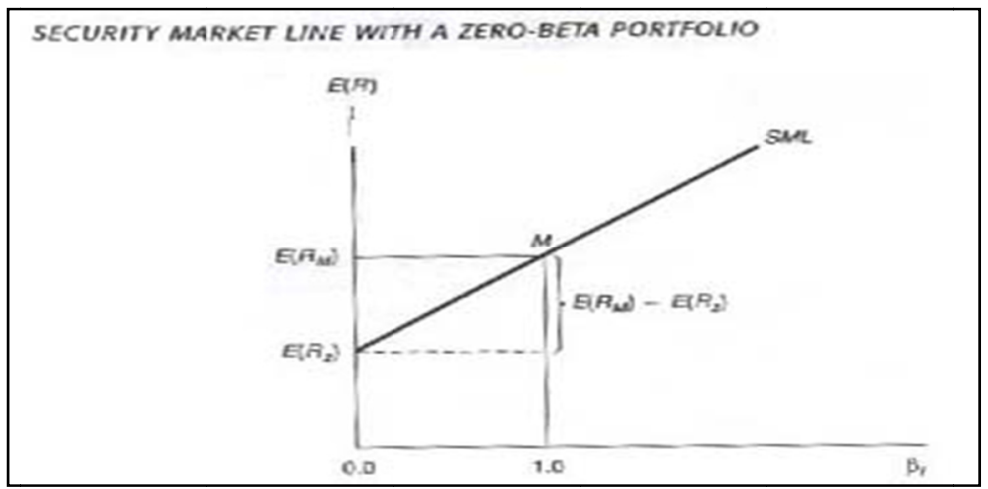

Figure 3. Zero Beta model

Source: Reilly and Brown (2003).

The beta of the portfolios that have returns uncorrelated with the market portfolio returns will be equal to zero. Investors will select from these portfolios with zero beta, the portfolios with the minimum risk. These portfolios of zero beta do not affect the Capital Market Line (CML) but another line is created called the Security Market Line (SML), as shown in figure (3). The intercept of this line with the y-axis is the expected return of a portfolio with zero beta. The return of this portfolio with zero beta will be higher than the risk-free asset. The slope of the line is flat as the difference between the market return and risk free return is small (Reilly \& Brown, 2003).

\subsection{Transaction Costs}

Reilly and Brown (2003) show that one of the CAPM assumptions is that there are no transaction costs, so investors will buy or sell mispriced securities until they again plot on SML. For example, if a stock plots above the SML, it is under priced so investors should buy it and bid up its price until its estimated return is in line with its risk until it plots on SML. With transaction costs, investors will not correct all mispricing because in some instances the cost of buying and selling the mispriced security will offset any potential excess return. Securities will plot very close to the SML- but not exactly on it. SML will be a band of securities rather than a single line (as shown in figure 4), the width of the band is function of the amount of the transactions costs. The existence of transaction costs also will affect the extent of diversification by investors. 


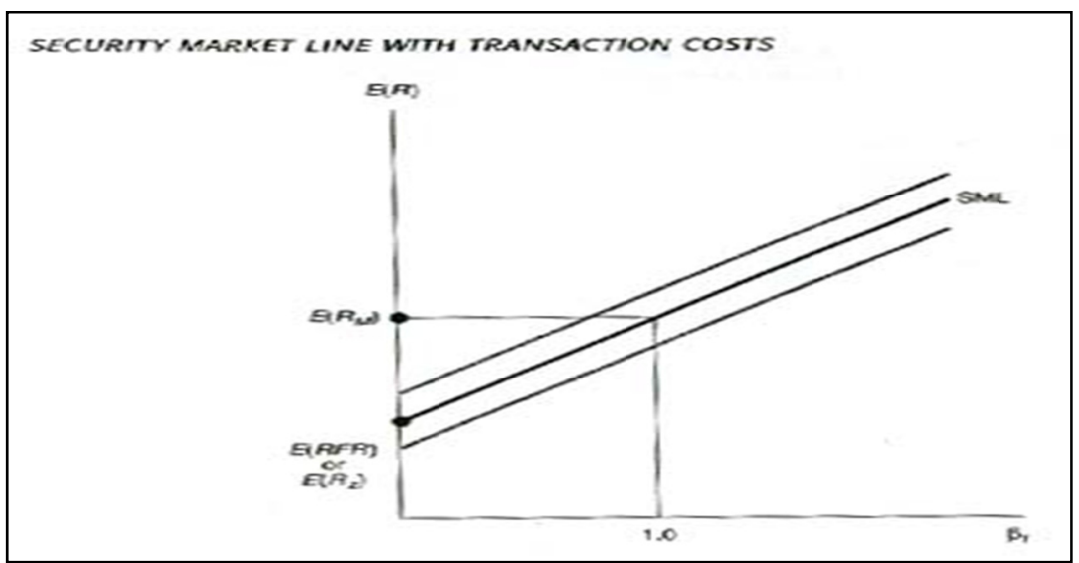

Figure 4. Effect of transaction costs

Source: Reilly and Brown (2003).

\subsection{Heterogeneous Expectations and Planning Periods}

Reilly and Brown (2003) argue that if the assumption of homogeneous expectations among investors is relaxed, in other words, investors will not have the same expectations about the future cash flows of the security, then every investor will have a different CML and SML determined according to their expectations about the distribution of returns. This will be graphically represented by a set of parallel lines beside each other. The distances between these lines will become narrower as investor expectations are more aligned together.

\subsection{Taxes}

Reilly and Brown (2003) suggest that the rate of return used through the model was pre-tax returns, but in fact, the actual returns for most investors are:

$$
E\left(R_{l}\right)(A T)=\frac{\left(P_{t}-P_{b}\right) \times\left(1-T_{c g}\right)+(D i v) \times\left(1-T_{i}\right)}{P_{b}}
$$

Where,

$\left(\mathrm{R}_{1}\right)(\mathrm{AT})=$ after tax rate of return;

$\mathrm{P}_{\mathrm{t}}=$ ending price;

$\mathrm{P}_{\mathrm{b}}=$ beginning price;

$\mathrm{T}_{\mathrm{cg}}=$ tax on capital gain or loss;

$\mathrm{T}_{\mathrm{i}}=$ tax on ordinary income.

The authors state that tax rates differ between individuals and institutions that do not pay taxes, the original pre-tax model is correctly specified- that is, $\mathrm{Tc}_{\mathrm{g}}$ ad $\mathrm{T}_{\mathrm{i}}$ take on values of zero. Because investors have heavy tax burdens, this could cause major differences in the CML and SML among investors.

Miller and Scholes (1982) re-examine some recent tests of whether holders of shares with higher dividend yields receive higher risk-adjusted rates of return to compensate for the heavier taxes on dividend payments than on long-term capital gains. They use short-run measures of dividend yield that is, measures that seek to deduce the differential tax burden over long term capital gains from differences in rates of return on shares that do and shares that do not pay a cash dividend during the return interval. They show that such measures are inappropriate for that purpose. Any yield related effects associated with such measures must arise from sources other than the long-term tax differential. For the short-run measures considered here, the yield-related effects found in some tests are traced to biases, one of a fairly subtle kind, introduced by divided announcement effects.

Black and Scholes (1974) find no significant relation between stocks returns and divided yield or dividend pay-out. Their results thus lent support to neither of two contending hypotheses about divided effect- the conventional view that the market prefers to obtain the income from stock as dividends and the country view, widely held among academics that the market demands higher returns on dividend- paying shares to compensate for tax penalties on divided income. 


\section{Critique of the CAPM}

The CAPM has been criticized in many studies for the assumptions of unrestricted risk-free borrowing and lending (Note 1), investors are maximizing one-period investment and focus only on risk and return of one-period portfolio (Note 2), whether market Betas explain the expected returns, and the proxy of market portfolio of all risky assets (Note 3). Furthermore, Fama and French (1997) find evidence that the estimates of the cost of equity capital for specific industries using the CAPM are imprecise with standard errors of more than 3 percent per year, due to uncertainty about the true expected risk premiums and imprecise estimates of industry betas. They argue that the estimates of the cost of equity are surely even less precise for individual firms and projects.

Fama and French (2004) illustrate that CAPM equation measures a relation between the expected returns of an asset and the market portfolio return. However, the market portfolio is criticized because it is based on unrealistic assumptions such as one-period investment, and unrestricted risk-free borrowing and lending. Fama and French (2004) conclude that most of the important models are built on unrealistic assumptions which must be practically tested.

\subsection{Unrestricted Risk-Free Borrowing and Lending}

Black (1972) asserts that the possibility of borrowing and lending unlimited funds at a risk free is unrealistic and develops another version of the CAPM without risk-free borrowing or lending. Black (1972) results show that unrestricted short sales of risky assets will lead to efficient market portfolio. The market portfolio is simply consisting of the efficient portfolios which investors select from the efficient frontier in case there is no risk free asset.

\subsection{Relation between Market Beta and Expected Return}

The different versions of the CAPM developed by Sharpe, Lintner and Black agree that market portfolio is the efficient portfolio that will trade off between risk and return. This indicates that variability in the security and portfolio expected returns will be only explained by changes in market beta and not any other variables.

To test whether market Betas explain expected returns, the following empirical work starting in the late 1970s is reviewed. The studies criticize the CAPM and the developed version of the CAPM by Black (1972) and argue that the variability in expected return is unrelated to market beta.

Basu's (1977) finds that the earnings per price ratio provides different evaluation for the common stocks from the CAPM, and argues that the common stocks with high earnings per price ratio have higher future returns than estimated by the CAPM. Likewise, Banz (1981) finds a relation between firm size and its average return and shows that the average return for small size firm stocks, measured by price multiplied by outstanding shares as proxy for market capitalization, is higher than measured by the CAPM. Thus, the size effect of Banz (1981) finds that small size firm stocks have higher average returns than large size firm stocks given their estimated beta. Similarly, Bhandari (1988) argues that highly leveraged firms generate high returns relative to their market Betas, and reports empirical evidence that high debt ratios, proxied by the debt book value to equity market value, are high returns relative to market beta. In U.S.A. firms, Statman (1980) and Rosenberg, Reid, and Lanstein (1985) document that the average returns on stocks are positively related to the ratio of a firm's book value of common equity to its market value, in other words, firms with high ratio of book value of common stock to the market value of equity have high average returns that are not explained by their betas. Chan, Yasushi, and Josef (1991) also find that there is a strong relation between the book to market equity ratio and the cross-section of average returns on Japanese stocks.

Ball (1978) determines a prime limitation of the CAPM is that market betas are imperfect and insufficient to explain the change in expected returns, and suggests that earnings to price, debt to equity and book-to-market ratios are good determinants for the expected returns. On the other hand, Kothari, Shanken, and Sloan (1995) support the Sharpe and Lintner version of CAPM and argue that the insignificant relation between the average return and beta suggested by some studies may refer to some limitations or luck and could not be generalized. But Fama and French (2004) argue that there is strong evidence that other variables like size, leverage, book-to-market equity, and earnings-price ratios can explain the variation in expected return which beta fails to interpret.

Fama and French (1992) confirm that size, earnings-price, debt-equity and book-to-market ratios can be used along with the market beta to explain the variation in stock returns using cross section regression approach. Using the time-series regression approach on portfolios sorted according to stock price ratios, Fama and French 
(1996) report the same result.

\subsubsection{Three Factor Model}

Fama and French (1993) propose a three-factor model for expected returns, in their model they add two factors to the CAPM to explain better the returns of the portfolio. Fama and French (1993) include the size and book-to-market equity to the market risk in order to better measure the return of the stock. Small stocks and stocks with high book to market ratio as proxy for firm value reflect risks that are not explained by beta the market systematic risk and market return. Empirically, they provide evidence that the covariance between returns is higher for small firms stocks than the covariance of returns in large size firms, and similarly, covariance of returns is higher for high value stocks measured by the book to market ratio than the covariance of returns in a low book to market stocks. Therefore, the three factor model includes the firm size, value of firm and the market risk factor used in the CAPM.

\subsection{Investors Care about Mean and Variance for Only Single-Period Portfolio}

Fama and French (2004) clarify that the CAPM is based on a number of unrealistic assumptions; one of these assumptions is that investors focus only on measuring the risk (variance) and return (mean) of one-period portfolio returns which is an extreme assumption. It is reasonable that investors also focus on how their portfolio return interacts with their income and future investment opportunities, so a portfolio's return variability fails to capture important dimensions of risk. Accordingly, market beta is not completely describing an asset's risk, and the differences in beta are unable to clarify all the differences in the expected return. Consequently, other versions are evolved as an extension for the CAPM in attempt to explain the average returns.

\subsubsection{ICAPM as an Extension of the CAPM}

Merton's (1973) intertemporal capital asset pricing model (ICAPM) is an extension of the CAPM. The ICAPM has a different assumption about investor objectives. In the CAPM, investors care only about the wealth their portfolio produces at the end of the current period. In the ICAPM, investors are not only concerned about their end-of-period payoff, but also with the opportunities they will have to consume or invest this payoff. Thus, when choosing a portfolio at the current time, ICAPM investors consider how their wealth in the future might vary with future variables, including their income, the prices of consumption goods and the nature of portfolio opportunities in the future, and also provides future expectations. Therefore, Merton's (1973) ICAPM shows that investors act to maximize the expected utility of lifetime consumption and who can trade continuously in time. The assumption of continual trading in assets through time is not assumed in the traditional model. The author shows that, unlike the one-period model, current demands are affected by the possibility of uncertain changes in future investment opportunities.

Fama (1996) comments on Merton's (1973) paper in which Merton developed an intertemporal model (the ICAPM) that uses utility maximization to get exact multifactor predictions of expected security returns. Fama (1996) shows that Merton gets exact results without assuming the market portfolio is perfectly diversified. Fama finds Merton's approach difficult due to the continuous-time methods used, and concludes that as in the CAPM, the relation between expected return and multifactor risks in the ICAPM is the condition on the weights for securities that holds in any multifactor-efficient portfolio, applied to the market portfolio M. And just as market equilibrium in the CAPM requires that M is efficient portfolio that trade-off between the risk and return of the portfolio, in the ICAPM, market prices indicate that portfolio M is multifactor-efficient. Fama (1996) shows that Merton's ICAPM can be built on similar intuition like the powerful intuition of the CAPM which centers on Markowitz (1959) concept of mean-variance-efficiency. ICAPM investors hold multifactor-efficient portfolios that generalize the notion of portfolio efficiency. Like CAPM investors, ICAPM investors dislike wealth uncertainty, but ICAPM investors are also concerned with hedging more specific aspects of future consumption-investment opportunities, such as the relative prices of consumption goods and the risk-return tradeoffs they will face in capital markets. Furthermore, ICAPM investors demand high expected return and low risk like the CAPM investors. However ICAPM investors also care about the movement of the returns of the portfolio with other dynamic variables. Therefore the optimal portfolio will be a factor in many variables and have largest range of possible expected returns.

\subsection{The Market Proxy Problem}

Finding a reasonable proxy for the market portfolio that is on the minimum variance frontier is one of the main problems that will rise when applying the CAPM, that is, identifying which risky assets that should be included in the risky portfolio to be used as a proxy for the market portfolio will be the main concern. As suggested in the literature, the market portfolio of all risky assets should include stocks, bonds, coins, real estate, art, stamps, 
antiques, and any other marketable risky asset.

For example, Roll (1977) argues that it is not theoretically clear which assets should be included in the market portfolio, and most studies use unreliable proxies that does not reflect the true market portfolio, therefore, the CAPM could not be verified. On the other side, Stambaugh (1982) tests the CAPM using wider range of market portfolios that includes more risky assets, such as; U.S. common stocks, corporate and government bonds, preferred stocks, real estate and other assets, and finds that tests of the CAPM are not sensitive or varying with the inclusion of other assets and extending the market portfolio beyond the common stocks. Fama and French (2004) comment on Stambaugh's (1982) results regarding insensitivity of market portfolio returns to adding ore types of risky assets beyond the common stock, that the market proxies used are limited to U.S. assets. If international capital markets are open, the market portfolio should include international assets. Fama and French (1998) find, however, that betas for an international stock market portfolio are unable to clarify why stocks with high book-to-market or high earnings-price ratios have higher average returns around the world.

\section{Extensions from Capital Asset Pricing Model}

Since the introduction of the CAPM many studies attempt to test it empirically and criticize the assumptions of the theory, as a result many other versions of the CAPM have been developed to overcome the unrealistic assumptions.

Black (1972) develops another version of Sharpe and Lintner CAPM by relaxing one of the CAPM assumptions, and shows that borrowing with the risk free rate is not a practical or realistic assumption. Instead, Black (1972) allows for the use of the unrestricted short sales of risky assets. Breeden (1979) and Lucas (1978) extend the traditional CAPM and develop the Consumption Capital Asset Pricing Model (CCAPM) which links between consumption and stock returns, thus, it relies on the aggregate consumption in order to understand and predict future asset prices instead of the market portfolio's return in the traditional CAPM. Breeden, Gibbons, and litzenberger (1989) examine the empirical implications of the consumption-oriented capital asset pricing model (CCAPM), and compare its performance with a model based on the market portfolio.

Merton (1973) develops an extension of the CAPM, the Intertemporal Capital Asset Pricing Model (ICAPM) that uses utility maximization to get exact multifactor predictions of expected security returns. The CAPM assumes that investors choose portfolios that produces return in the future while in the ICAPM investors are concerned not only with their end-of-period payoff, but also with the opportunities they will have to consume or invest the payoff. Thus, when choosing a portfolio at time t-1, the ICAPM investors consider how their wealth at time $t$ might vary with future variables including labour income, the prices of consumption goods and the nature of portfolio opportunities at $t$.

Fama and French (1993 \& 1996) propose a three-factor model for estimating the expected returns of risky assets, their model includes more factors that affect the variability in portfolios average return than in the sharpe-Lintner version. The three factors model includes the firm size, book-to-market equity ratio and other price ratios.

Finally, an important version for the CAPM is the Arbitrage pricing theory which will be discussed in more details in the next section.

\subsection{An Overview of the Ross Arbitrage Pricing Theory}

Although the CAPM has been one of the most frequently used and useful theory, but many empirical studies point out some drawbacks and limitations in the model as the relation between risk, which is measured by Beta, and the asset return. Some empirical evidences indicate that additional risk variables or different risk proxies should be taken into consideration and added to the model. In addition, many studies criticize the tests of the model and its ability to estimate the return of the portfolio and capture the variability in its expected return. Those studies refer this problem to the market return proxy and the dependence on a market portfolio of risky assets that is not verified and also the problem of borrowing and lending at the risk free rate.

Banz (1981) shows that portfolios consisting of stocks of small size firms, that indicate low market capitalization, have better performance than large stock portfolios on a risk adjusted basis. Similarly, Basu (1977) documents that stocks with low price-earnings ratio outperform high stocks. Fama and French (1992) demonstrate that value stocks measured by high book value-to- market price ratios stocks tend to produce higher risk adjusted returns than growth stocks proxied by low book-to-market ratios, and these return differentials occur in an efficient market. The CAPM empirical problems may reflect theoretical failings as a result of many simplified assumptions, and raise the need for an alternative asset pricing theory.

Shanken (1982) argues that the CAPM is not truly testable in a strict sense. Much of this acceptance can be attributed to the persuasive analysis of Roll (1977), who argues that the CAPM is not testable unless the market 
portfolio of all assets is used in the empirical test. The APT of Ross has been proposed as a testable alternative to the CAPM. Roll and Ross (1980) explain that the APT demonstrates that since any market equilibrium must be consistent with no arbitrage profits, then every equilibrium will be characterized by a linear relationship between each asset's expected return and its return's response amplitude, or loadings, on the common factor. Huberman and Wang (2005) show that the APT was developed primarily by Ross (1976a, 1976b). It is a one-period model in which every investor believes that the stochastic properties of returns of capital assets are consistent with a factor structure. Ross (1980) argues that if equilibrium prices offer no arbitrage opportunities over static portfolios of the assets, then the expected returns on the assets are approximately linearly related to the factor loadings. The factor loadings, or betas, are proportional to the returns' covariances with the factors.

Reilly and Brown (2003) illustrate that the APT differs from the CAPM in that it is less restrictive in its assumptions. It assumes that each investor will hold a unique portfolio with its own particular array of betas, as opposed to the identical "market portfolio", while the CAPM designated a single risk factor which is the market risk in order to explain the volatility of returns for an individual security or portfolio of securities. The main difference between the two models, the CAPM and the APT, is that the latter includes more risk factors or multiple dimensions of risk inherent in the investments while the CAPM relies on a single market risk factor which is the systematic investment risk when estimating individual securities return or portfolio returns.

\subsubsection{Basics of the APT Model}

A brief discussion for the assumptions and critiques of the model are provided below. The theory assumes that asset returns can be estimated by depending on a random process shown by a various number of risk factors included in the model and are expected to affect the returns generated by all assets. For example, these multiple risk factors may consist of, inflation, changes in interest rates, growth in gross domestic product (GDP), or political and economic events, that are expected to strongly affect the returns of all assets.

The APT contends that there are many such factors that affect returns, in contrast to the CAPM, where the relevant risk to measure is the covariance of the asset with the market portfolio (presented by the asset's beta). The beta measures the sensitivity of each asset return to the market portfolio return, or how the security return reacts to a specific single common factor.

\subsubsection{Assumptions of the Model}

Reinganum (1981) addresses three assumptions. First, capital markets are perfectly competitive. Secondly, investors always prefer more wealth to less wealth with certainty. And lastly, the stochastic process generating asset returns can be represented as a K- factor model. The major assumptions, which are used in the development of CAPM, and are not required in the APT: 1) Investors have utility functions, 2) Normally distributed security retrns. 3) An efficient market portfolio that contains all risky assets.

Roll and Ross (1980) determine the differences between CAPM and APT, the APT is based on a linear return generating process as a first principle, and it neither requires utility assumptions nor is it restricted to a single period. Though consistent with every conceivable prescription for portfolio diversification, no particular portfolio plays a role in the APT. Unlike the CAPM, there is no requirement that the market portfolio be mean variance efficient. The authors go further that there are two major differences between the APT and the original Sharpe diagonal model, a single factor generating model. First, the APT allows more than just one generating factor. Second, the APT demonstrates that since any market equilibrium must be consistent with no arbitrage profits, every equilibrium will be characterized by a linear relationship between each asset's expected return and its return's response amplitudes, or loadings, on the common factor.

\subsubsection{Critique of the Arbitrage Pricing Theory}

The Arbitrage Pricing Model considers multiple risk factors that are expected to have impact on the returns of all assets. When the APT is applied, these risk factors are not identified. Regarding the testability of the APT, for example, Shanken (1982) examines whether the APT is more susceptible to testing than the CAPM and argues that each of the models has a problem with testing, specifically, to test the CAPM, the true market portfolio should be used; whereas, and to test the APT, the relevant factor that affects security returns should be identified.

Dybvig and Ross (1985) argue that the APT has been proposed as an alternative to the mean-variance CAPM. Their paper considers the testability of the APT and points out the irrelevance for testing of the approximation error. Shanken (1985) responds that it is a set of equilibrium APT pricing models that are testable but arbitrage-based models are not testable. In other words, Dybvig and Ross (1985) have shifted the focus to equilibrium models that are testable and they ignore the differences between these models and the original arbitrage theory. 


\section{Conclusions}

Although the CAPM is criticized for the assumptions of the model such as; the unrestricted risk-free borrowing and lending, investors care only about the risk and return of one-period portfolio returns, market Betas explain the expected returns, in addition to the proxy of market portfolio of all risky assets. However, it is widely used and many industries depend on this model to determine its price in the market.

Furthermore, the empirical evidence finds some disadvantages in using the CAPM and APT. For example, the equity market risk premium, which is the incremental return that investors require for holding risky equities rather than risk free securities, is not observable and depends on estimating future cash flows, generally the estimation of the equity market risk premium is controversial (King, 2009).

Using the single factor CAPM, which is used by the Federal Reserve System to estimate the cost of equity for banks in six countries over the period 1990-2009, shows wide variation across banks, highlighting the difficulty of estimating expected returns using the CAPM. Moreover, using the CAPM in estimating the cost of equity capital for specific industries is imprecise due to uncertainty about the true expected risk premiums and imprecise estimates of industry betas (Fama \& French, 1997). In spite of the empirical evidence which suggests weakness of the CAPM, and the problems concerning the model assumptions, the CAPM remains a useful tool for estimating the cost of capital, evaluating the investment performance and event studies of efficient market (Moyer, McGuigan, \& Kretlow, 2001 and Campbell, Lo, \& MacKinlay, 1997).

It is recommended that the CAPM should be used carefully when estimating the required rate of return of a stock. Furthermore, testing the CAPM and the APT should be applied on the different industries in the MENA region, whereas researchers and investors should ensure that these models are applicable in their countries.

\section{References}

Ball, R. (1978). Anomalies in relationships between securities' yields and yield-surrogates. Journal of Financial Economics, 6(2), 103-126. http://dx.doi.org/10.1016/0304-405X(78)90026-0

Banz, R. W. (1981). The relationship between return and market value of common stocks. Journal of Financial Economics, 9(1), 3-18. http://dx.doi.org/10.1016/0304-405X(81)90018-0

Basu, S. (1977). Investment performance of common stocks in relation to their price-earnings ratios: a test of the efficient market hypothesis. Journal of Finance, 12(3), 129-156.

Bhandari, L. C. (1988). Debt/Equity ratio and expected common stock returns: empirical evidence. Journal of Finance, 43(2), 507-528. http://dx.doi.org/10.1111/j.1540-6261.1988.tb03952.x

Black, F., \& Scholes, M. (1974). The Effects of dividend yield and dividend policy on common stock prices and returns. Journal of Financial Economics, 1-22. http://dx.doi.org/10.1016/0304-405X(74)90006-3

Black, F. (1972). Capital market equilibrium with restricted borrowing. The Journal of Business, 45(3). http://dx.doi.org/10.1086/295472

Breeden, D. T. (1979). An international asset pricing model with stochastic consumption and investment

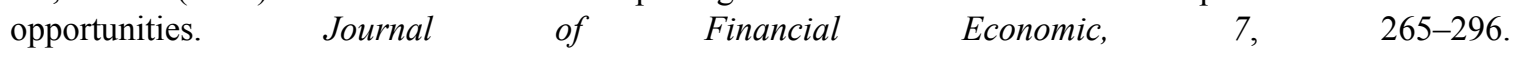
http://dx.doi.org/10.1016/0304-405X(79)90016-3

Breeden, D. T., Gibbons, M. R., \& litzenberger, R. H. (1989). Empirical test of the consumption-oriented CAPM. Journal of Finance, 44(2). http://dx.doi.org/10.1111/j.1540-6261.1989.tb05056.x

Brennan, M. J. (1971). Capital market equilibrium with divergent borrowing and lending rates. Journal of financial and Quantitative Analysis, 6(5). http://dx.doi.org/10.2307/2329856

Campbell, J. Y., Lo, A. W., \& MacKinlay, A. C. (1997). The Econometrics of Financial Markets. Princeton, New Jersey: Princeton University Press.

Chan, L. C., Yasushi, H., \& Josef, L. (1991). Fundamentals and stock returns in Japan. Journal of Finance, 46(5), 1739-1789. http://dx.doi.org/10.1111/j.1540-6261.1991.tb04642.x

Dybvig, P. H., \& Ross, S. A. (1985). Yes, the APT is testable. Journal of Finance, 40(4), 1173-1188. http://dx.doi.org/10.1111/j.1540-6261.1985.tb02370.x

Fama, E. F. (1996). Multifactor portfolio efficiency and multifactor asset pricing. Journal of Financial and Quantitative Analysis. 31(4), 441-465. http://dx.doi.org/10.2307/2331355

Fama, E. F., \& French, K. R. (1992). The Cross-section of expected stock returns. Journal of Finance, 47(2), 427-465. http://dx.doi.org/10.1111/j.1540-6261.1992.tb04398.x 
Fama, E. F., \& French, K. R. (1993). Common risk factors in the returns on stocks and bonds. Journal of Financial Economics, 33(1), 3-56. http://dx.doi.org/10.1016/0304-405X(93)90023-5

Fama, E. F., \& French, K. R. (1996). Multifactor explanations of asset pricing anomalies. Journal of Finance, 51(1), 55-84. http://dx.doi.org/10.1111/j.1540-6261.1996.tb05202.x

Fama, E. F., \& French, K. R. (1998). Value versus growth: the international evidence. Journal of Finance, 53(6), 1975-1999. http://dx.doi.org/10.1111/0022-1082.00080

Fama, E. F., \& French, K. R. (2004). The Capital Asset Pricing Model: theory and evidence. Journal of Economic Perspectives, 18(3), 25-46. http://dx.doi.org/10.1257/0895330042162430

Fama, E., \& French, K. (1997). Industry costs of equity. Journal of Financial Economics, 43, $153-193$. http://dx.doi.org/10.2469/dig.v27.n4.158

Friend, I., \& Blume, M. (1970). Measurement of portfolio performance under uncertainty. American Economic Review, $L X(4)$, 561-575.

King, M. R. (2009). The cost of equity for global banks: a capm perspective from 1990 to 2009. BIS Quarterly Review, 9, 59-73.

Kothari, S. P., Shanken, J., \& Sloan, R. G. (1995). Another look at the cross-section of expected stock returns. Journal of Finance, 50(1), 185-224. http://dx.doi.org/10.1111/j.1540-6261.1995.tb05171.x

Lintner, J. (1965). The Valuation of risk assets and the selection of risky investments in stock portfolios and capital budgets. The Review of Economics and Statistic, 47(1). http://dx.doi.org/10.2307/1924119

Lucas, R. E. (1978). Asset prices in an exchange economy. Econometrica, 46, 1429-1445.

Markowitz, H. (1952). Portfolio selection. Journal of Finance, 7(1), 77-99. http://dx.doi.org/10.1111/j.1540-6261.1952.tb01525.x

Merton, R. C. (1973). An intertemporal capital asset pricing model. Econometrica, 41(5), 867-887. http://dx.doi.org/10.2307/1913811

Miller, M. H., \& Scholes, M. S. (1982). Dividends and taxes: some empirical evidence. Journal of Political Economy, 90(6). http://dx.doi.org/10.1086/261114

Moyer, R. C., McGuigan, J. R., \& Kretlow, W. J. (2001). Contemporary financial management (8th ed.). Ohio: South-Western, Cincinnati.

Reilly, F., \& Brown, K. (2003). Investment analysis portfolio management (7th ed.). Thomson, South-Western.

Reinganum, J. (1981). Market structure and the diffusion of new technology. The Bell Journal of Economics, 12, 618-624. http://dx.doi.org/10.2307/3003576

Roll, R. (1977). A critique of the asset pricing theory's tests' part I: On past and potential testability of the theory. Journal of Financial Economics, 4(2), 129-176. http://dx.doi.org/10.1016/0304-405X(77)90009-5

Roll, R., \& Ross, S. A. (1980). An empirical investigation of the arbitrage pricing theory. Journal of Finance, 35(5), 1073-1103. http://dx.doi.org/10.1111/j.1540-6261.1980.tb02197.x

Rosenberg, B., Reid, K., \& Lanstein, R. (1985). Persuasive evidence of market inefficiency. Journal of Portfolio Management, 11(3), 9-17. http://dx.doi.org/10.3905/jpm.1985.409007

Shanken, J. (1982). The Arbitrage Pricing Theory: is it testable? Journal of Finance, 37(5), 1129-1140. http://dx.doi.org/10.1111/j.1540-6261.1982.tb03607.x

Shanken, J. (1985). Multi-Beta CAPM or equilibrium APT?: A reply. Journal of Finance, 40(4), 1189-1196. http://dx.doi.org/10.1111/j.1540-6261.1985.tb02371.x

Sharpe, W. F. (1964). Capital asset prices: A theory of market equilibrium under conditions of risk. Journal of Finance, 19(3), 425-442. http://dx.doi.org/10.1111/j.1540-6261.1964.tb02865.x

Stambaugh, R. F. (1982). On the exclusion of assets from tests of the two-parameter model: A sensitivity analysis. Journal of Financial Economics, 10(3), 237-268. http://dx.doi.org/10.1016/0304-405X(82)90002-2

Stattman, D. (1980). Book values and stock returns. The Chicago MBA, 4(1), 25-45.

Tobin, J. (1958). Liquidity preference as behavior toward risk. Review of Economic Studies, 25(2), 65-86. http://dx.doi.org/10.2307/2296205 


\section{Notes}

Note 1. Black (1972) asserts that unrestricted risk-free borrowing and lending is an unrealistic assumption and develops a version of the CAPM without risk-free borrowing or lending.

Note 2. Unreasonable assumption as investors also care about how their portfolio return covaries with labour income and future investment opportunities (Merton, 1973). Therefore, market beta is not a complete description of an asset's risk and the expected return are not completely explained by differences in beta.

Note 3. Roll (1977) argue that assets to be included in the market portfolio are not well defined theoretically in the literature, in addition to data limitations that hinder the inclusion of assets to the market portfolio. In the same vein, Stambaugh (1982) includes many assets in the market portfolio when testing the CAPM and concludes that the results of the CAPM are affected substantially when adding other assets to the market portfolio other than common stocks.

\section{Copyrights}

Copyright for this article is retained by the author(s), with first publication rights granted to the journal.

This is an open-access article distributed under the terms and conditions of the Creative Commons Attribution license (http://creativecommons.org/licenses/by/3.0/). 